\title{
Burden of shoulder and/neck pain among school teachers in Ethiopia
}

Melaku Hailu Temesgen ${ }^{1 *}$, Gashaw Jember Belay ${ }^{1}$, Asmare Yitayeh Gelaw ${ }^{1,2}$, Balamurugan Janakiraman ${ }^{1}$ and Yaregal Animut ${ }^{3}$

\begin{abstract}
Background: Shoulder and neck pain are reported as the most common occupational-related health problem and cause of morbidity, absenteeism from work among school teachers worldwide. School teachers represent an occupational group, who are exposed and appears to have prevalent shoulder and/or neck pain due to their daily work tasks and the nature of work. There is a scant epidemiological study regarding shoulder and neck pain among school teachers in Ethiopia. Therefore, this study was set out to assess the prevalence and associated factors of shoulder and/or neck pain among school teachers of Gondar town in North West Ethiopia.
\end{abstract}

Method: An institutional based cross-sectional study was conducted from December 2016 to January 2017, a structured questionnaire adapted from the Nordic musculoskeletal questionnaire was distributed to 848 primary and secondary school teachers in Gondar town, Northwest Ethiopia. To assess the burden of shoulder and/neck pain, data were collected using a self-administered questionnaire and physical measures like height and weight were also measured during data collection. Independent variables which had significant association were identified using logistic regression model.

Result: A total of 754 teachers participated, with a mean age of $42 \pm 9.73$ years (88.9\% response rate). Previous 12 months self-reported prevalence of shoulder and/ neck pain among school teachers was $57.3 \%$ with $95 \% \mathrm{Cl}(53.4-61.0 \%)$. Regular physical exercise ( $\mathrm{OR}=0.18,95 \% \mathrm{Cl}: 0.08-0.42)$, teaching experience $(\mathrm{OR}=2.85,95 \% \mathrm{Cl}$ : 1.09-7.42), static head down posture ( $\mathrm{OR}=2.26,95 \% \mathrm{Cl}: 1.55-3.33)$, elevated arm over shoulder ( $\mathrm{OR}=2.71,95 \% \mathrm{Cl}$ : 1.86-3.95), prolonged sitting $(\mathrm{OR}=1.50,95 \% \mathrm{Cl}: 1.02-2.23)$ and hypertension $(\mathrm{OR}=2.18,95 \% \mathrm{Cl}: 1.24-3.82)$ were factors found to be significantly associated with shoulder and/neck pain.

Conclusion and recommendation: More than half of the study participants self-reported to have suffered shoulder and neck pain in the previous 12 months. Teaching experience, static head down posture, elevated arm over shoulder, and hypertension are likely to be significantly associated with shoulder and/ neck pain among school teachers in Ethiopia. Engaging in regular physical exercise has a protective effect against the shoulder and/or neck pain. Therefore, school authorities are recommended to provide facilities to enhance physical activity among school teachers and also provide adjustable board and classroom materials.

Keywords: Shoulder and/neck pain, School teachers, Posture, Hypertension, Ethiopia

\footnotetext{
* Correspondence: physiomelaku2008@gmail.com

'Department of Physiotherapy, School of Medicine, College of Medicine and

Health Sciences University of Gondar, P. O. Box: 196, Gondar, Ethiopia

Full list of author information is available at the end of the article
}

(c) The Author(s). 2019 Open Access This article is distributed under the terms of the Creative Commons Attribution 4.0 International License (http://creativecommons.org/licenses/by/4.0/), which permits unrestricted use, distribution, and reproduction in any medium, provided you give appropriate credit to the original author(s) and the source, provide a link to the Creative Commons license, and indicate if changes were made. The Creative Commons Public Domain Dedication waiver (http://creativecommons.org/publicdomain/zero/1.0/) applies to the data made available in this article, unless otherwise stated. 


\section{Background}

Among all the occupational-related health problems, pain in the shoulder and neck is the most common cause of morbidity and absenteeism from work in many countries [1-3]. From the general musculoskeletal disorders (MSD), shoulder-neck pain is the specific and particular pain among the different working population with its multifactorial bio-psychological origin and socio-economic costs [4-8].

School teachers represent an occupational group, which are exposed and appears to be at the risk of suffering shoulder and/or neck pain (SNP) due to their daily work tasks [4] . In a single day, a wide variety of duties and responsibilities may be carried out by school teachers which involve significant use of head down postures, such as prepare lessons, frequent reading, assessing/marking students and writing on blackboard under unfavorable working conditions, especially in low-middle income countries (LMIC's) [3, 4, 9, 10] . While performing such daily tasks repeatedly for a long period of time using abnormal posture; they might develop pain or discomfort around shoulder/neck body segments [11] .

A systematic review conducted on "musculoskeletal disorders among teachers" from 13 countries(3- from America, 4- from Europe, 5- from Asia and Australia) reported that the prevalence of MSD among school teachers was between 40 and $90 \%$ [11] . A study in China reported that 12-month neck and/or shoulder pain prevalence among school teachers was $66.7 \%$ [12]. Upper back, shoulder, and neck MSD were common and reported at similar rates 52.6, 52.5, and 50.8\% respectively in a cross-sectional study of Botswana school teachers [9].

Socio-demographic factors such as gender, age, body mass index (BMI), individual factors like smoking and drinking habit, physical exercise, work-related factors for instance working hours, head down posture, overhead activities and psycho-social factors like poor colleagues and supervisor support, low job satisfaction are considered as associated factors of shoulder and/ neck musculoskeletal pain (MSP) among school teachers in different epidemiological studies [13-17].

Due to this vague pain, school teachers suffer a low quality of life, frequent sick leave, functional impairments, absenteeism, early retirement, disability and health cost. Our extensive search revealed scarce published regional works reporting the prevalence of SNP among school teachers in the sub-Saharan region and none were found in Ethiopia. Hence, the aim of this study was to determine the prevalence and identify factors associated with SNP among primary and secondary school teachers in North West Ethiopia.

\section{Method}

\section{Study design, period and study area}

An institutional based cross-sectional study was conducted in Gondar town, Northwest Ethiopia from December 8, 2016, to January 30, 2017. Gondar town is a historical terrain in the country and located at $727 \mathrm{~km}$ Northwest of Addis Ababa, the capital city of Ethiopia. According to the 2007 Ethiopian census report, Gondar has 206,987 total population [18]. Administratively the town is divided into 12 administrative areas. It has one University, 2 Colleges, 1 Technical and Vocational school, 14 secondary schools and 65 primary schools. The total numbers of teachers working in primary and secondary schools of both private and governmental schools of Gondar town were about 1500 [19].

\section{Source and study population}

All school teachers working in both primary (1-8 grade) and secondary (9-10 grade) schools of private and Governmental institutions in Gondar town were used as source population and Randomly selected teachers who were working in the proportionally nominated schools were study subjects.

\section{Sample size and sampling method}

The sample size of the study was calculated using a single population proportion formula by considering $50 \%$ prevalence of SNP, 95\% confidence interval and 5\% margin of error. Finally, the sample size of 848 was obtained by addition of $10 \%$ non-response rate, and a design effect of 2 .

Multi-stage sampling technique was employed to select the study participants. First, Schools in the town were stratified into primary and secondary schools based on the level of the institution. Then each stratum was further classified into private and governmental schools. Subsequently, 22 schools were proportionally selected using simple random sampling from each stratum. From the selected schools the samples were proportionally recruited based on the total number of teachers in that school using an alphabetical list obtained.

\section{Data collection procedures and quality control}

A structured self-administered questionnaire (Additional file 1) was distributed to collect the data. The questionnaire was first prepared in English language and then translated to Amharic (local language) and again back to English by language experts and was checked for the consistency. Tools used to assess shoulder/neck pain was adapted from the standardized Nordic questionnaire and modified to local context [20]. Before the actual data collection a pre-test was carried out with $10 \%$ of power calculated sample out of the study area. Intensive training was provided to data collectors and supervisors for 2 days. Six physiotherapists were recruited to distribute 
the self-administered questionnaire (including the written consent form with a single page in front of the questionnaire), to assemble the filled questionnaire, and take physical measures. Weight was measured using floor weighing scale (Electrolux, Korea) with participants standing without shoes and wearing light clothing and recorded to the nearest $0.5 \mathrm{Kg}$. Height was measured using stadiometer at standing upright with the head in the Frankfort plane and recorded with an approximation of 1 $\mathrm{cm}$. The data collection process was closely monitored by the principal investigator $(\mathrm{MH})$ and the supervisors throughout the data collection period. Filled questionnaires were checked daily for completeness of information and conflicts were reported to data collectors.

\section{Data analysis}

Data was coded and entered into Epi info software version 7.0 and analyzed using IBM Statistical Package for Social Sciences (SPSS) version 23 for windows. The results were presented using text, frequency distribution tables, and graph for descriptive statistics. Logistics regression model was used to identify factors associated with shoulder and/or neck pain. Independent variables with a $p$-value less than $<0.2$ in the bivariate logistic regression were fitted into the multivariable logistic regression analysis for controlling the possible main effect of confounders and interaction terms was used to examine the potential associations.. Results were considered statistically significant when $95 \%$ confidence intervals not containing unity (equal to $p$-value $<0.05$ ) for both main effects and interaction terms.

\section{Operational definitions}

Burden: it is defined as the prevalence of shoulder and neck pain.

Shoulder and/ neck pain: ache, pain, or discomfort felt at a time in the shoulder and neck (cervico-brachial region) in the last 12 months.

\section{Result}

\section{Socio-demographic characteristics}

A total of 848 questionnaires were distributed, of which 754 teachers responded hence the response rate was $88.9 \%$. Majority of the study participants $(57.8 \%)$ were females. The mean age of the respondents was 42 years (SD \pm 9.732 years). Nearly, one-third of them (32.8\%), were in the age group of 31-40 years. The majority of teachers were from primary schools and governmental schools 77.5 and $83.4 \%$ respectively (Table 1 ).

\section{Behavioral and physical characteristics}

Only $3.2 \%$ of the teachers were current smokers and $7.7 \%$ were previous smokers. A minority of the respondents (7.4\%) were having a habit of drinking alcohol. A
Table 1 Socio-demographic characteristics of school teachers in Gondar town January, 2017 ( $N=754)$

\begin{tabular}{|c|c|c|}
\hline Variables & Frequency $=\mathrm{N}$ & Percent $=\%$ \\
\hline \multicolumn{3}{|l|}{$\overline{\text { Sex }}$} \\
\hline Male & 318 & $42.2 \%$ \\
\hline Female & 436 & $57.8 \%$ \\
\hline \multicolumn{3}{|l|}{ Pregnant } \\
\hline Yes & 14 & $3.2 \%$ \\
\hline No & 422 & $96.8 \%$ \\
\hline \multicolumn{3}{|l|}{ Age } \\
\hline$<31$ & 119 & $15.8 \%$ \\
\hline $31-40$ & 246 & $32.8 \%$ \\
\hline $41-50$ & 214 & $28.5 \%$ \\
\hline$>50$ & 175 & $22.9 \%$ \\
\hline \multicolumn{3}{|l|}{ Marital status } \\
\hline Single & 96 & $12.7 \%$ \\
\hline Married & 624 & $82.8 \%$ \\
\hline Others & 34 & $4.5 \%$ \\
\hline \multicolumn{3}{|c|}{ Educational level } \\
\hline Certificate & 9 & $1.2 \%$ \\
\hline Diploma & 387 & $51.3 \%$ \\
\hline Degree & 346 & $45.9 \%$ \\
\hline Master & 12 & $1.6 \%$ \\
\hline \multicolumn{3}{|l|}{ Salary } \\
\hline $2000-4000$ & 155 & $20.6 \%$ \\
\hline $4001-6000$ & 517 & $68.6 \%$ \\
\hline$>6001$ & 82 & $10.9 \%$ \\
\hline \multicolumn{3}{|l|}{ Handedness } \\
\hline Right & 734 & $97.3 \%$ \\
\hline Left & 20 & $2.7 \%$ \\
\hline \multicolumn{3}{|l|}{ School } \\
\hline Primary & 584 & $77.5 \%$ \\
\hline Secondary & 170 & $22.5 \%$ \\
\hline \multicolumn{3}{|l|}{ Organization } \\
\hline Private & 125 & $16.6 \%$ \\
\hline Public & 629 & $83.4 \%$ \\
\hline
\end{tabular}

small proportion of $(7.2 \%)$ participants were involved in regular physical exercises for more than $150 \mathrm{~min}$ per week. More than half (55\%) of the participant's BMI was categorized as normal weight followed by overweight (Fig. 1).

\section{Work -related characteristics and comorbidities}

More than one-thirds of the teachers (37.4\%) have 10-19 years of teaching experience with a overall mean of 18.79 \pm 10.24 years. One hundred thirty-nine $(18.4 \%)$ of respondents reported being involved in more than $30 \mathrm{~h}$ of 


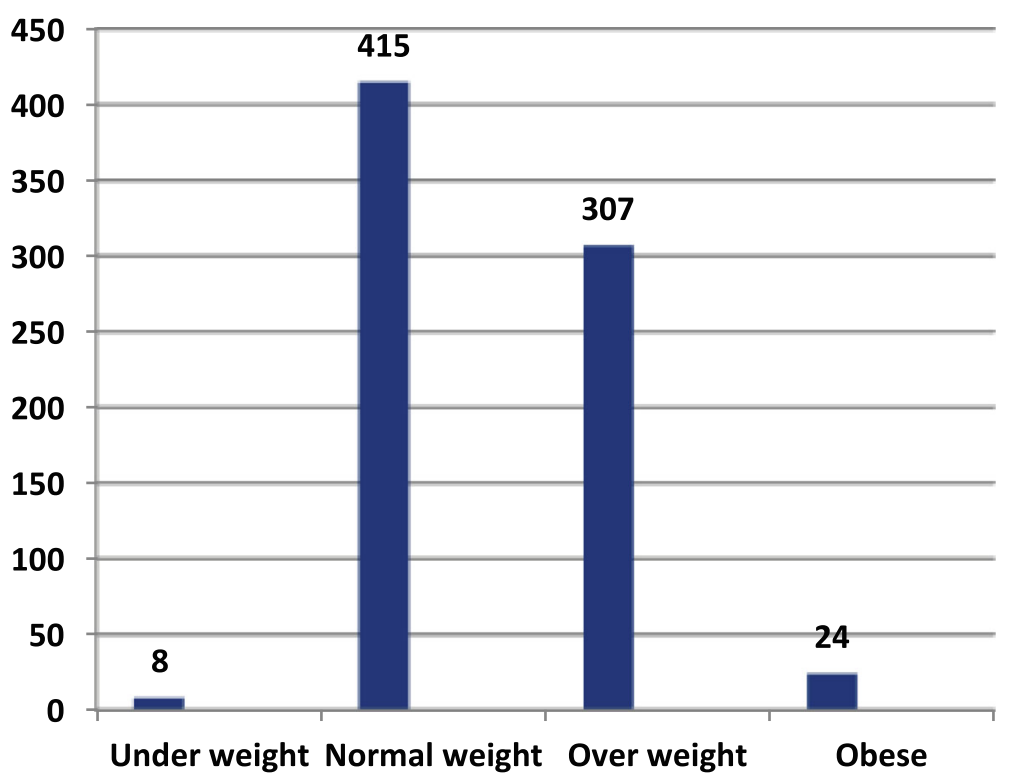

Fig. 1 This figure is a bar graph for body mass index categories of school teachers in Gondar town, Ethiopia 2017 ( $N=754)$

teaching in a week. The majority (70\%), of teachers, indicated that they were using static head down posture and elevated arm over the shoulder (69.4\%) for more than $2 \mathrm{~h}$ in a day while they were teaching students. Among the participants 15 and $17 \%$ of school teachers self-reported to have been diagnosed with diabetes and hypertension respectively (Table 2).

Regarding psychosocial characteristics, 281 (37.1\%) of them were satisfied by their profession and 290 (38.5\%) of school teachers were sometimes supported by their supervisors (Table 3).

\section{Prevalence and distribution of shoulder and/neck pain among school teaches}

Previous 12 months self-reported prevalence of shoulder and/ neck pain among school teachers was 57.3\% (95\% CI: 53.4-61.0\%). The prevalence of SNP was higher among female teachers, primary public school teachers, teachers who have more than 30 years of teaching experiences 59.7, 60.42 and $77.2 \%)$ respectively. Teachers with body mass index $\geq 30$ reported higher (91.6\%) prevalence of shoulder and/ or neck pain.

\section{Factors associated with shoulder and/neck pain}

In the bivariate logistic regression analysis, self-reported SNP was significantly associated with, age, marital status, monthly salary, working organization, previous smoker, habit of drinking alcohol, doing physical exercise, teaching experience, teaching hour per week, using static head down posture, elevated arm over the shoulder, prolonged sitting, diabetes mellitus, hypertension and respiratory diseases. However, in the multivariate logistic regression analysis, self-reported SNP was associated significantly $(p<0.05)$ with regular physical exercise $(\mathrm{OR}=0.18$, 95\% CI: $0.08-0.42)$, teaching experience $(\mathrm{OR}=2.85,95 \% \mathrm{CI}$ : 1.09-7.42), static head down posture $(\mathrm{OR}=2.26,95 \% \mathrm{CI}$ : $1.55-3.33)$, elevated arm over the shoulder $(\mathrm{OR}=2.71,95 \%$ CI: $1.86-3.95)$, prolonged sitting $(\mathrm{OR}=1.50,95 \% \quad \mathrm{CI}$ : 1.02-2.23) and hypertension $(\mathrm{OR}=2.18,95 \% \mathrm{CI}$ : 1.24-3.82) (Table 4).

\section{Discussion}

This is the preliminary study that investigated the prevalence of shoulder and/or neck pain and the association of individual, health, and occupational characteristics among primary and secondary school teachers was assessed. The previous 12 months self-reported prevalence of shoulder and/or neck pain among primary and secondary school teachers was 57.3\% (95\% CI: 53.4-61.0), the results indicated that SNP is a common occupational health problem among school teachers and suggestive of some specific participant, health, and working condition may increase the prevalence rate among Ethiopian school teachers. Though, studies that reported prevalence rate of SNP are distinctively scant. $[12,16,21]$ The findings of this study is similar to a study done among Malaysian school teachers reporting $60 \%$ prevalence [22]. However, the prevalence of this study is higher than the studies conducted in China (48.7\%) [12], Saudi Arabia (45.2\%) [23], Japan (35.4\%) [24] and Brazil (31.6\%) [25]. This difference observed in prevalence rate of SNP could due to the differences in educational system, study design, the facility provided for the teachers at their institution or social, cultural, and economic differences between Ethiopia and other countries., 
Table 2 Work related characteristics and comorbidities of school teachers in Gondar town, January, 2017 ( $N=754)$

\begin{tabular}{|c|c|c|c|c|c|}
\hline & \\
\hline Variables & Frequency N (\%) & Percent $=\%$ & Variables & Frequency $=\mathrm{N}$ & Percent $=\%$ \\
\hline Teaching experience (year) & & & Supervisor support & & \\
\hline $2-9$ & 151 & $20.0 \%$ & Always & 45 & $6.0 \%$ \\
\hline $10-19$ & 282 & $37.4 \%$ & Often & 208 & $27.6 \%$ \\
\hline $20-29$ & 163 & $21.6 \%$ & Sometimes & 290 & $38.5 \%$ \\
\hline$>=30$ & 158 & $21.0 \%$ & Seldom & 150 & $19.9 \%$ \\
\hline Teaching hours/ week & & & Never & 61 & $8.1 \%$ \\
\hline$<=30$ & 615 & $81.6 \%$ & Social support & & \\
\hline$>30$ & 139 & $18.4 \%$ & Always & 13 & $1.7 \%$ \\
\hline Number of students in class & & & Often & 79 & $10.5 \%$ \\
\hline $21-30$ & 42 & $5.6 \%$ & Sometimes & 217 & $28.8 \%$ \\
\hline $31-40$ & 129 & $17.1 \%$ & Seldom & 232 & $30.8 \%$ \\
\hline$>40$ & 564 & $77.3 \%$ & Never & 213 & $28.2 \%$ \\
\hline Static head down posture(>2hr/day) & & & Co-worker support & & \\
\hline Yes & 528 & $70.0 \%$ & Always & 39 & $5.2 \%$ \\
\hline No & 226 & $30.0 \%$ & Often & 196 & $26.0 \%$ \\
\hline Elevated arm (>2hr/day) & & & Sometimes & 270 & $18.0 \%$ \\
\hline Yes & 523 & $69.4 \%$ & Seldom & 136 & $15.0 \%$ \\
\hline No & 231 & $30.6 \%$ & Never & 113 & $18.7 \%$ \\
\hline Prolonged sitting (>4hr./day) & & & Job satisfaction & & \\
\hline Yes & 247 & $32.8 \%$ & Highly satisfied & 66 & $37.1 \%$ \\
\hline No & 507 & $67.2 \%$ & Satisfied & 281 & $25.9 \%$ \\
\hline Comfortable upper back support & & & Neutral & 263 & $11.3 \%$ \\
\hline Yes & 134 & $17.8 \%$ & Unsatisfied & 90 & $7.0 \%$ \\
\hline No & 620 & $82.2 \%$ & Highly unsatisfied & 54 & $6.0 \%$ \\
\hline
\end{tabular}

Diabetes mellitus

$\begin{array}{lll}\text { Yes } & 113 & 15.0 \% \\ \text { No } & 641 & 85.0 \%\end{array}$

Hypertension

Yes

No

Respiratory diseases

Yes

No

\section{5}

$8.6 \%$

Previous history of surgery

$\begin{array}{ll}\text { Yes } & 12 \\ \text { No } & 742\end{array}$

Previous history of Trauma

Yes

No
$1.6 \%$

$98.4 \%$

742

$4.6 \%$

$95.4 \%$
Table 3 Psychosocial characteristics of school teachers in Gondar town, 2017 ( $n=754)$

The prevalence reported in this study was lower than the prevalence reported in studies conducted in India (73.5\%) [26] and Taiwan (63.4\%) [27]. The possible reason for the observed dissimilarity could be due to difference in study design, study population, and teaching conditions, the Indian study included six school levels (starting from primary to technical schools) of teacher, and the Taiwan study included teachers by purposive sampling and used mailing for data collection from special education schools. Special education teachers work with children who have a variety of mental, emotional, physical, and learning disabilities which is demanding with special challenges.

The present study also indicated that habit of doing physical exercise has a positive effect on the shoulder and/or neck pain among school teachers and the risk of developing SNP reduced by $82 \%$ as compared to those with no exercise.. This result was consistent with studies done in Turkey [28], China [12] and Botswana [9]. The possible reasons may be exercises can improve strength, flexibility, pain threshold, and makes muscles and ligaments stronger to support the

In addition, working hours, the way in which work was organized, children teacher ratio, and the protective factors involved contribute to the differences observed in comparison to the present study. 
Table 4 Factors associated with SNP among school teachers in Gondar town with bivariate and multivariate logistic regression analysis, $2017(N=754)$

\begin{tabular}{llll}
\hline SNP & COR $(95 \% \mathrm{Cl})$ & AOR $(95 \% \mathrm{Cl})$ & $p$-value \\
YES NO & & \\
\hline
\end{tabular}

\begin{tabular}{cccllll}
\hline Age & & & & & \\
$<=30$ & 35 & 82 & 1 & & \\
$31-40$ & 123 & 124 & $2.38(1.49,3.79)$ & $1.13(0.56,2.29)$ & 0.737 \\
$41-50$ & 142 & 73 & $4.67(2.89,7.58)$ & $1.66(0.71,3.91)$ & 0.245 \\
$>50$ & 132 & 41 & $7.73(4.56,13.09)$ & $1.82(0.67,5.05)$ & 0.236 \\
Marital status & & & & & \\
Single & 26 & 70 & 1 & & \\
Married & 383 & 241 & $4.28(2.65,6.90)$ & $1.59(0.85,3.01)$ & 0.148 \\
Other & 23 & 11 & $5.63(2.41,13.14)$ & $2.44(0.89,6.65)$ & 0.082 \\
Salary & & & & & \\
2000-4000 & 57 & 98 & 1 & & \\
4001-6000 & 322 & 195 & $2.84(1.96,4.12)$ & $1.01(0.58,1.75)$ & 0.976 \\
$>6000$ & 53 & 29 & $3.14(1.79,5.49)$ & $0.72(0.33,1.57)$ & 0.410 \\
Organization & & & & & \\
Public & 374 & 255 & $1.69(1.15,2.49)$ & $0.82(0.50,1.36)$ & 0.447 \\
Private & 58 & 67 & 1 & & \\
Previous smoker & & & & \\
Yes & 43 & 15 & $2.26(1.23,4.15)$ & $1.41(0.68,2.89)$ & 0.347 \\
No & 389 & 307 & 1 & &
\end{tabular}

Alcohol consumer

$\begin{array}{llllll}\text { Yes } & 40 & 16 & 1.95(1.07,3.55) & 1.33(0.64,2.78) & 0.450 \\ \text { No } & 392 & 306 & 1 & & \end{array}$

Physical exercise

$\begin{array}{llllll}\text { Yes } & 9 & 45 & 0.13(0.06,0.27) & \mathbf{0 . 1 8}(\mathbf{0 . 0 8}, \mathbf{0 . 4 2}) & \mathbf{0 . 0 0 0 *} \\ \text { No } & 423 & 277 & 1 & & \end{array}$

Teaching experience

$\begin{array}{lllllll}2-9 & 47 & 104 & 1 & & & \\ 10-19 & 161 & 215 & 2.94(1.94,4.47) & \mathbf{1 . 9 6}(\mathbf{1 . 0 3}, \mathbf{3 . 6 9}) & \mathbf{0 . 0 3 9 *} \\ 20-29 & 102 & 61 & 3.70(2.32,5.91) & 1.58(0.70,3.57) & 0.268 \\ >=30 & 122 & 36 & 7.49(4.52,12.45) & \mathbf{2 . 8 5}(\mathbf{1 . 0 9 , 7 . 4 2 )} & \mathbf{0 . 0 3 2 *}\end{array}$

Teaching hours/week

$<=30 \quad 365 \quad 250 \quad 1$

$\begin{array}{llllll}>30 & 67 & 72 & 1.57(1.09,2.27) & 0.66(0.43,1.03) & 0.067\end{array}$

Static head down posture

$$
\begin{array}{lllllll}
\text { Yes } & 342 & 186 & 2.78(2.02,3.83) & \mathbf{2 . 2 6}(\mathbf{1 . 5 5}, \mathbf{3 . 3 3}) & \mathbf{0 . 0 0 0 *} \\
\text { No } & 90 & 136 & 1 & &
\end{array}
$$

\begin{tabular}{|c|c|c|c|c|c|}
\hline Yes & 342 & 181 & $2.96(2.15,4.08)$ & $2.71(1.86,3.95)$ & $0.000 *$ \\
\hline No & 90 & 141 & 1 & & \\
\hline \multicolumn{6}{|c|}{ Prolonged sitting } \\
\hline Yes & 161 & 86 & $1.63(1.19,2.23)$ & $1.50(1.02,2.23)$ & $0.041 *$ \\
\hline No & 271 & 236 & 1 & & \\
\hline
\end{tabular}

Elevated arm over shoulder
Table 4 Factors associated with SNP among school teachers in Gondar town with bivariate and multivariate logistic regression

\begin{tabular}{|c|c|c|c|c|c|}
\hline & \multicolumn{2}{|l|}{ SNP } & \multirow[t]{2}{*}{ COR $(95 \% \mathrm{Cl})$} & \multirow[t]{2}{*}{ AOR (95\% Cl) } & \multirow[t]{2}{*}{$p$-value } \\
\hline & YES & NO & & & \\
\hline \multicolumn{6}{|c|}{ Diabetes mellitus } \\
\hline Yes & 84 & 29 & $2.44(1.55,3.82)$ & $1.22(0.70,2.11)$ & 0.479 \\
\hline No & 348 & 293 & 1 & & \\
\hline \multicolumn{6}{|c|}{ Hypertension } \\
\hline Yes & 105 & 23 & $4.17(2.59,6.73)$ & $2.18(1.24,3.82)$ & $0.006^{*}$ \\
\hline No & 327 & 299 & 1 & & \\
\hline \multicolumn{6}{|c|}{ Respiratory disease } \\
\hline Yes & 49 & 16 & $2.45(1.36,4.39)$ & $1.58(0.80,3.12)$ & 0.184 \\
\hline No & 383 & 306 & 1 & & \\
\hline
\end{tabular}
analysis, 2017 ( $N=754$ ) (Continued)

* $=p$-value is $<0.05, C O R$ crud odds ratio, $\mathrm{Cl}$ confidence interval, $A O R$ adjusted odds ratio, SNP shoulder neck pain

neck and shoulder alignment for optimal functioning and prevents injury $[9,29]$.

Studies conducted in Botswana [9], Egypt [30], and Saudi Arabia [23] reported an association between teaching experience and the prevalence of SNP. Similarly in the present study, there is a significant association between SNP and increasing year of teaching experience. Teachers with more than 30 years of teaching experience were 2.85 times more likely to develop SNP than those with less than 10 years of teaching experience and those who have 10-19years teaching experience were 1.96 times more likely to develop SNP when compared to those with less than 10 years teaching experience. The possible reasons could be effect of aging, age-related degenerative changes, declined tissue healing, thinning of cartilage, and cumulative trauma to neck and shoulder structures due to workload. Most available studies reported an association of age and length of employment with SNP. More so, in this study and Ethiopia, teachers start teaching at an early age after completion of a diploma or bachelor degree. Hence, the possibility of a higher length of employment, longer exposure to occupational- related hazards, and eventually job-related musculo-skeletal disorders at much younger age compared with many other countries. $[4,5,21]$

Teachers spending more than $2 \mathrm{~h}$ per day with a static head down posture for reading, paper evaluations, scoring, and preparing class works is associated with shoulder and/or neck pain in the present study. This result was similar to a study in China [31]. The reason might be sustained head down posture could result in straining of neck structures causing discomforts, muscle stiffness or tightness around cervico-brachial region eventually pain $[29,32]$. In addition, the student-teachers ratio was higher, $81.2 \%$ of teachers included in this study had more than 40 students in a class. 
In this study elevated arm (arm above shoulder) was significantly associated with shoulder and/ or neck pain. Elevating arm above shoulder during writing on board was 2.71 times more likely to develop a chance of SNP compared to not elevating arm above shoulder. This result was in similar to studies done in Botswana [9] and Egypt [30]. Possible reasons could be, working with raised arms above unsupported shoulder for a long time can cause friction, tension, and strain over cervico-brachial regions $[27,28,33]$. This is normally observed in teachers' daily routine to write on the board. This mechanism can cause teachers to develop discomfort in the cervico-brachial regions, which is even made worse by daily overwork and less rest time.

The other work-related factor associated with shoulder and/or neck pain was prolonged sitting. Teachers those who reported prolonged sitting $(>4 \mathrm{Hr}$.) were 1.50 times more likely to develop SNP. This result was comparable with a study done in China among school teachers [12] . The possible reason might be teachers sitting on uncomfortable chair and table tends to develop stiffness and discomfort. In this study, more than 3/4th $(82.2 \%)$ of teachers were reported as they were not using comfortable support during sitting.

In this study, teachers those who self-reported to have hypertension as diagnosed by physician were significantly associated with shoulder and/or neck pain. Teachers with self-reported hypertension were 2.18 times more likely to develop SNP compared to those who had no hypertension. This result is consistent with a study done in Malaysia among secondary school teachers [22] . Hypertension by itself due to more pressure in the vessels of cervical region or along with postural syndrome might result in shoulder and neck pain. Few physicians even report that neck musculatures could play a crucial role in controlling blood pressure. Hence, the symptoms of hypertension by itself could result in shoulder and neck pain or it could even worsen the severity of pain during repetitive daily school tasks. This study has provided an insight into the frequency of shoulder and neck pain among the school teaching community in a resource-limited country. Though $88.9 \%$ of the calculated sample was reached, with the higher than anticipated prevalence being reached post hoc power analysis showed $100 \%$ power.

\section{Study limitations}

Considering the benefits of future research there are few limitations to be mentioned. Psychological factors, postural assessment, home and job site evaluations were not considered. These confounders could lead to a possible variation in the estimation of association among SNP and other variables. The cross-sectional nature does not allow inferring of causality and effect. This study also included both primary and secondary school teachers with variable working demands which might be a possible source of heterogeneity in the study sample. Hence the findings of this study should be interpreted with caution. Future studies should address these concerns and determine causality and effect among school teachers. Nevertheless, this is a preliminary work to provide a powered insight into the burden of shoulder and /neck pain among school teachers in Ethiopia.

\section{Conclusion}

In conclusion, this study showed that SNP is a common occupational-related health problem among both primary and secondary school teachers in Ethiopia. Work-related, and health characteristics like posture, health and working conditions such as teaching experience, using static head down posture, elevated arm over the shoulder, prolonged sitting during and hypertension were associated with shoulder and neck pain. Whereas engaging in regular physical exercise has a protective effect for shoulder pain. Related factors that may help explain SNP among school teachers should be explored by future studies. The school authorities are recommended to provide facilities to enhance physical activity among school teachers and also provide adjustable board and classroom materials. School teachers are recommended to develop awareness of related health hazards and encourage the habit of regular physical exercise.

\section{Additional file}

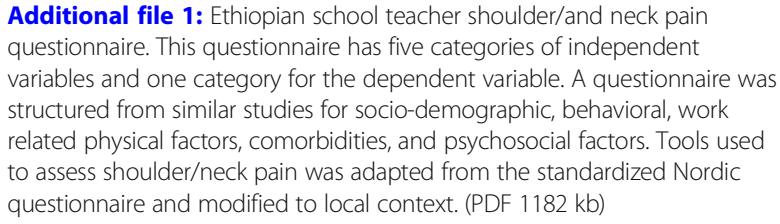

Additional file 1: Ethiopian school teacher shoulder/and neck pain questionnaire. This questionnaire has five categories of independent variables and one category for the dependent variable. A questionnaire was structured from similar studies for socio-demographic, behavioral, work related physical factors, comorbidities, and psychosocial factors. Tools used to assess shoulder/neck pain was adapted from the standardized Nordic questionnaire and modified to local context. (PDF $1182 \mathrm{~kb}$ )

\section{Abbreviations \\ AOR: Adjusted odds ratio; BMI: Body mass index; COR: Crude odds ratio; LMIC's: Low-Middle Income Countries; MSD: Musculo-skeletal disorder; MSP: Musculoskeletal pain; OR: Odd's ratio; PR: Prevalence ratio; SD: Standard deviation; SNP: Shoulder and/or neck pain; ULD: Upper limb disorder; WHO: World Health Organization; WRMSP: Work related musculo-skeletal pain}

\section{Acknowledgements \\ We are grateful to college of medicine and health sciences, University of Gondar for funding the project. We would like to express our very special thanks to all study participants for sparing their time during data collection, Gondar City Educational Office for providing us all the necessary information.}

\section{Funding}

This work was fully funded by University of Gondar. The funder has no role in the design of the study, data collection, and analysis, interpretation of data and in writing the manuscript. 


\section{Availability of data and materials}

Since this is a funded work, the raw data is property of University of Gondar. Data request can be arranged by the principal investigator for a reasonable formal request.

\section{Authors' contributions}

MHT wrote the proposal, coordinated the data collection activity, analyzed the data and drafted the paper. AYG, BJ, GJB, and YA revise the proposal and participated in the data collection, analysis and manuscript writing. All authors read and approved the final manuscript.

\section{Authors' information}

Melaku Hailu Temesgen - BSc PT, MSc PT, Lecturer of Physiotherapy, School of Medicine, College of Medicine and Health sciences, University of Gondar, Gondar, Ethiopia.

Balamurugan Janakiraman - BSC PT, MSC PT, Assistant professor of Physiotherapy, School of Medicine, College of Medicine and Health sciences, University of Gondar, Gondar, Ethiopia.

Asmare Yitayeh Gelaw - BSC PT, MSC PT, Assistant professor of Physiotherapy, School of Medicine, College of Medicine and Health sciences, University of Gondar, Gondar, Ethiopia.

Gashaw Jember Belay - BSc PT, MSc PT, Lecturer of Physiotherapy, School of Medicine, College of Medicine and Health sciences, University of Gondar, Gondar, Ethiopia.

Yaregal Animut - MPH in Epidemiology and Biostatistics, Lecturer of Epidemiology and Biostatistics, Institute of Public Health, College of Medicine and Health Sciences, University of Gondar, Gondar, Ethiopia.

\section{Ethics approval and consent to participate}

Ethical clearance was obtained from the ethical review committee of University of Gondar, College of Medicine and Health Sciences. Written informed consent was obtained from each of the study participants after being informed in detail about the objective, purpose, benefit, risk, and the confidentiality of information and the voluntary nature of participation. In addition, participants who had shoulder and/neck pain during the data collection time were advised and referred, for further care to physiotherapists at Gondar University hospital.

\section{Consent for publication}

Not applicable.

\section{Competing interests}

The authors declare that they have no competing interest.

\section{Publisher's Note}

Springer Nature remains neutral with regard to jurisdictional claims in published maps and institutional affiliations.

\section{Author details}

'Department of Physiotherapy, School of Medicine, College of Medicine and Health Sciences University of Gondar, P. O. Box: 196, Gondar, Ethiopia. ${ }^{2}$ Department of Epidemiology and Preventive Medicine, Monash University, Melbourne, Victoria, Australia. ${ }^{3}$ Department of Epidemiology and Biostatistics, Institute of Public Health, College of Medicine and Health Sciences, University of Gondar, Gondar, Ethiopia.

Received: 23 February 2018 Accepted: 2 January 2019 Published online: 10 January 2019

\section{References}

1. Sadeghian F, Raei M, Ntani G, Coggon D. Predictors of incident and persistent neck / shoulder pain in Iranian Workers: a cohort study. PLoS One. 2013;8(2):e57544.

2. Larsson B, Søgaard K, Rosendal L. Work related neck - shoulder pain: a review on magnitude, risk factors, biochemical characteristics, clinical picture and preventive interventions. Best Pract Res Clin Rheumatol. 2007; 21(3):447-63.

3. Erick PN. Smith DR. a systematic review of musculoskeletal disorders among school teachers. BMC Musculoskelet Disord. 2011;12(260):13-7.

4. Erick P, Smith D. Musculoskeletal disorder risk factors in the teaching profession : a critical review. OA Mysculoskeletal Med. 2013;1(3):1-10.
5. Erick PN, Smith DR. Musculoskeletal disorders in the teaching profession : an emerging workplace hazard with significant repercussions for developing countries. Ind Health. 2015;53:385-6.

6. Mayer J, Kraus T, Ochsmann E. Longitudinal evidence for the association between work-related physical exposures and neck and / or shoulder complaints : a systematic review. Int Arch Occup Env Heal. 2012;85:587-603.

7. P.M. Bongers, S ljmker, S. van den Heuvel BMB. Epidemiology of work related neck and upper limb problems : psychosocial and personal risk factors ( part I ) and effective interventions from a bio behavioural perspective ( part II ). J Occup Rehabil 2006;16:279-302.

8. Kraatz S, Lang J, Kraus T, Mu E. The incremental effect of psychosocial workplace factors on the development of neck and shoulder disorders a systematic review of longitudinal studies. Int Arch Occup Env Heal. 2013;86:375-95

9. Erick PN, Smith DR. The Prevalence and Risk Factors for Musculoskeletal Disorders among School Teachers in Botswana. Occup Med Heal. 2014;2:178.

10. TN P. Perceived occupational health problems among college teachers in Banke. 2014;

11. Mesaria S, Jaiswal N. Musculoskeletal disorders among teachers residing in various Nations : a review. Res J Recent Sci. 2015;4:23-7.

12. Yue P, Liu F, Li L. Neck / shoulder pain and low back pain among school teachers in China, prevalence and risk factors. BMC Public Health. 2012; 12(1):1 Available from: BMC Public Health.

13. Arvidsson I, Simonsen JG, Dahlqvist C, Axmon A, Karlson B, Björk J, et al. Cross-sectional associations between occupational factors and musculoskeletal pain in women teachers, nurses and sonographers. BMC Musculoskelet Disord. 2016;17(35). Available from:). https://doi.org/10.1186/ s12891-016-0883-4.

14. Hansson G-A, Balogh I, Ohlsson K, Granqvist L, Nordander C, Skerfving S, et al. Physical workload in various types of work: Part II. Neck, shoulder and upper arm. Int J Ind Ergon. 2009:1-15.

15. Bogaert I, De Martelaer K, Deforche B, Clarys P, Zinzen E. Associations between different types of physical activity and teachers ' perceived mental , physical , and work-related health. BMC Public Health. 2014;14:534.

16. Karakaya IÇ, Karakaya MG, Tunç E, Kintır M. Musculoskeletal problems and quality of life of elementary school teachers. Int J Occup Safty Ergon. 2015; 21(3):344-50.

17. Shuai J, Yue P, Li L, Liu F, Wang S. Assessing the effects of an educational program for the prevention of work-related musculoskeletal disorders among school teachers. BMC Public Health. 2014;14(1211):1-9.

18. Agency CS. Summary and statistical report of the 2007 population and housing census: population size by age and sex: Ethiopia AA. 2008.

19. Teresa Kisi Beyen MYM and YTZ. Low Back Pain and Associated Factors among Teachers in Gondar Town, North Gondar, Amhara Region, Ethiopia. Occup Med Heal Aff. 2013;

20. Kuorinka I, Jonsson B, Kilbom A, Vinterberg H. Standardised Nordic questionnaires for the analysis of musculoskeletal symptoms. Appl Ergon. 1987;18(3):233-7.

21. Ehsani F, Mohseni-Bandpei MA, Fernández-De-Las-Peñas C, Fernandez JK. Neck pain in Iranian school teachers: prevalence and risk factor. J Body Work Mov Ther. 2018;22:64-8.

22. Zamri EN, Moy FM, VCWH. Association between individual psychological and work psychosocial factors with self- reported musculoskeletal pains among secondary school teachers in Malaysia introduction di. PLoS One. 2015:12(2):1-17.

23. Darwish MA, Al-zuhair SZ. Musculoskeletal pain disorders among secondary school Saudi female teachers. Hindawi Poblishing Corp Pain Res Treat. 2013; 2013:13-8.

24. Ono Y, Imaeda T, Shimaoka M, Hiruta S. Associations of length of employment and working conditions with neck, shoulder and arm pain among nursery school teachers. Ind Health. 2002;40:149-58.

25. Albanita Gomes de Costa de Ceballos GBS. Factors associated with musculoskeletal pain among teachers : sociodemographics aspects, general health and well-being at work. Rev Bras Epidemol. 2015;18(3):702-15.

26. Mariammal T, Jaisheeba AA, Sornaraj R. Occupation influenced physical illness observed among the teachers of Thoothukudi town. Int J Pharm Tech Res. 2012;4(3):1274-8.

27. Cheng HK, Wong M, Yu Y, Ju Y. work-related musculoskeletal disorders and ergonomic risk factors in special education teachers and teacher ' $\mathrm{s}$ aides. BMC Public Health. 2016;16(137):1-9. Available from:. https://doi.org/10. 1186/s12889-016-2777-7. 
28. Korkmaz NC, Cavlak U, Telci EA. Musculoskeletal pain, associated risk factors and coping strategies in school teachers. Sci Res Essays. 2011;6(3):649-57.

29. Tsauo JY, Lee HY, Hsu JH, Chen CY, Chen CJ. Physical exercise and health education for neck and shoulder complaints among sedentary workers. J Rehabil Med. 2004;36(6):253-7.

30. Mo E, Ebied E. Work- related musculoskeletal pain among primary school Teachers : a recommended health promotion intervention for prevention and management. World J Nurs Sci. 2015;1(3):54-61.

31. Chiu TTW, Lam PKW. The prevalence of and risk factors for neck pain and upper limb pain among secondary school teachers in Hong Kong. J O ccup Rehabil. 2007:17:19-32.

32. Shaema HR, Appadurai S, Mamo Wubshet TT. Occupational exposures and related health effects. Ethiop J Heal Biomed Sci. 2008;1(1):41-6.

33. Cassou B, Derriennic F, Monfort C, Norton J, Touranchet A. Chronic neck and shoulder pain, age, and working conditions: Iongitudinal results from a large random sample in France. Occup Environ Med. 2002;59:537-44.

Ready to submit your research? Choose BMC and benefit from:

- fast, convenient online submission

- thorough peer review by experienced researchers in your field

- rapid publication on acceptance

- support for research data, including large and complex data types

- gold Open Access which fosters wider collaboration and increased citations

- maximum visibility for your research: over $100 \mathrm{M}$ website views per year

At BMC, research is always in progress.

Learn more biomedcentral.com/submissions 